\title{
Full scale measurements and simulations of the wind speed in the close proximity of the building skin
}

\author{
Radoslav Ponechal ${ }^{1, *}$ and Peter Juras ${ }^{1}$ \\ ${ }^{1}$ University of Zilina, Faculty of Civil Engineering, Department of Building Engineering and Urban \\ Planning, Univerzitna 8215/1, 01026 Zilina, Slovak Republic
}

\begin{abstract}
. 36 meteorological stations are located on the facade of the Research Centre building's from 2016. Weather stations measure basic climate parameters and wind velocity and direction using a powerful ultrasonic anemometers. These are located on the walls of the building oriented to four cardinal points at different heights and positions on the façade. The location selections were made with use of CFD simulation which analysed flow around the building. Thus they give faithful image of wind flow near the façade of five-storey office building. Such detailed measurements make it possible to achieve high accurate calibration of CFD models and measurements in the wind tunnel. This paper describes these meteorological stations in detail. First outputs from measurement in autumn are published and analysed.
\end{abstract}

\section{Introduction}

Wind engineering deals with interaction between wind in the atmospheric boundary layer and human works on the earth surface. Good knowledge of fluid mechanics is the fundamental background necessary for the detailed understanding of interaction among wind flow and civil engineering structures of buildings.

\subsection{Experimental methods in wind engineering}

Wind caused loads on the buildings can be studied by different methods, such as wind tunnel measurements, experiments on the real buildings, which can be full or part scale and CFD (computational fluid dynamics) simulations. Aerodynamic boundary layer wind tunnels are simulating atmospheric flows in the lowest part of the atmosphere and are often used for the evaluation of wind loads on buildings.

Computational methods made big progress through the last decade and are often better, cheaper and more used compared to the ABL wind tunnel measurements [1]. Before the computer era, full-scale measurements were widely used. Nowadays, these measurements are expensive, time consuming and less used. But several distinctive features of the wind

\footnotetext{
*Corresponding author: radoslav.ponechal@,fstav.uniza.sk
} 
have been found from the full-scale measurements in the past [2]. Sometimes wind tunnel experiments have some limitations, which may be solved by full scale experiments. Such cases include the pressure difference over permeable facade or roof or the local conditions in small areas. Another reason, when the full scale experiments are still useful is validation and verification of wind tunnel experiment or other simulations.

For wind tunnel measurement and simulation especially, experienced supervisor for representation of the results is needed. On the other hand, full scale experiments are limited with the availability of sufficient wind conditions, large amount of time, effects of surrounding terrain, measuring devices and involved costs. Full scale measurements on city buildings, where the fluctuating characteristics of wind were subject of investigation, have been performed in many countries $[3,4,5,6]$.

\subsection{Wind velocity and buildings}

The unsteady character of wind regime, combined with the additional unsteadiness of the flow after the wind impacts on a building generates highly fluctuating velocities depending on the flow characteristics and the building configuration. The unsteadiness of the wind on the windward and leeward side of the façade is clear from the graph in Fig. 1.

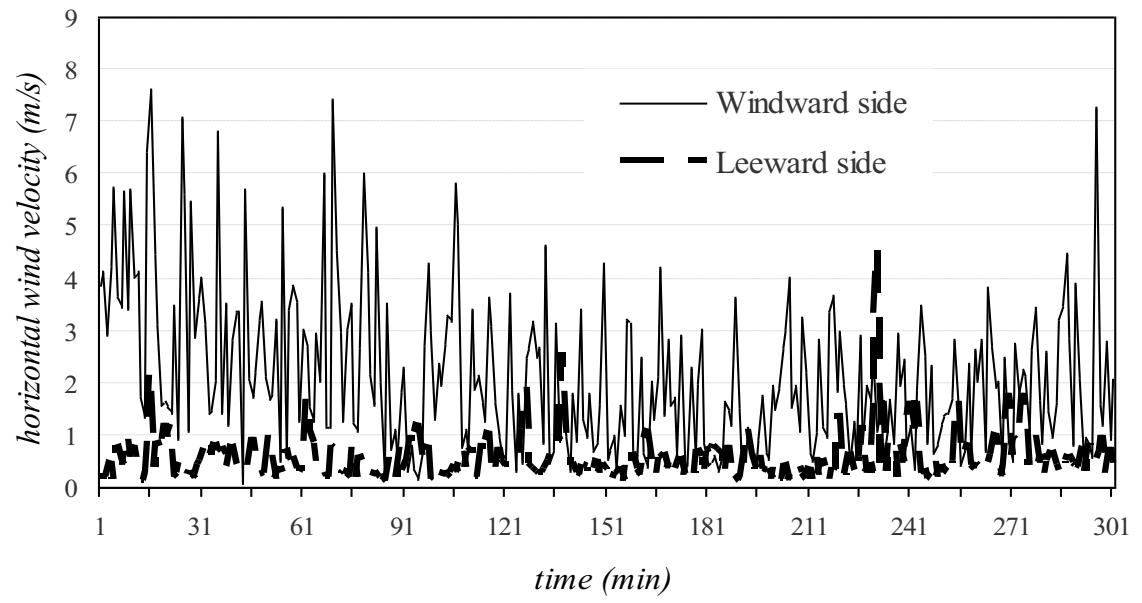

Fig. 1. Measured wind velocity on the façade of Research Centre building in Zilina.

The wind velocity can be considered as it consisted of mean wind speed and fluctuating component (turbulence). It may be caused by its own movement or ground roughness. The turbulence caused by ground roughness is higher in rougher terrain then in smoother terrain or flat open terrain and it decreases with height above the terrain. The turbulence is characterized by turbulence intensity $I(h)$, defined as:

$$
I(h)=\sigma(h) / u_{m}(h)
$$

where $u_{m}(h)$ is mean wind speed at elevation $h$ and $\sigma(h)$ is standard deviation value of fluctuating velocity.

\subsection{Wind structure}

The mean wind speed changes in time, large fluctuations occur in a period of several hours or days. The variation of wind height is almost nil. The stationarity of the mean wind speed 
over periods of 10 minutes to many hours is the significant characteristic of the wind structure, since it forms the basic idea of wind tunnel testing.

Fig. 2 shows a record of wind velocity obtained from measurements at three different heights in the close proximity of the building skin.

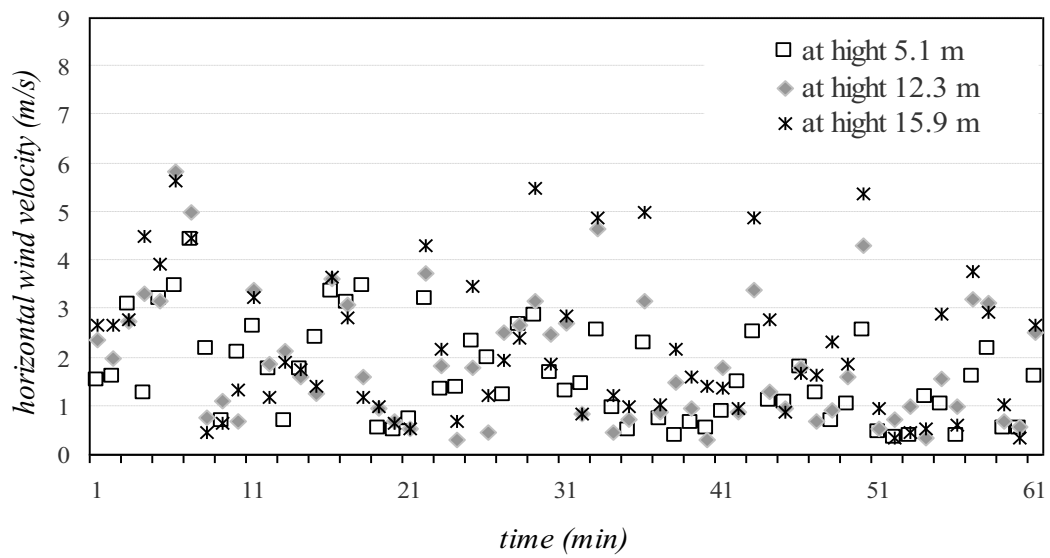

Fig. 2. Wind velocity from full scale measurements in three different heights from ground level on the north side of Research Centre building in Žilina.

\section{Full scale measurement}

\subsection{Test side and the building}

The building is situated north of the city center. The main part of building has dimensions: height $19.2 \mathrm{~m}$, width $22.9 \mathrm{~m}$ and depth $16.4 \mathrm{~m}$. The building has almost an exact east-west orientation so that the short facades are the north and south facade. Building consist of 5 storey administrative part and low rise laboratory part as can be seen in Fig. 3 from northwest side. Some surroundings in the prevailing wind directions consist of low-rise buildings (maximum height $20 \mathrm{~m}$ ) and trees up to $25 \mathrm{~m}$ height. A view towards west side is in Fig. 4. The building has a partially aerated façade with tiles and partially ETICS with coating. Porous surface is produced by windows with external blinds.

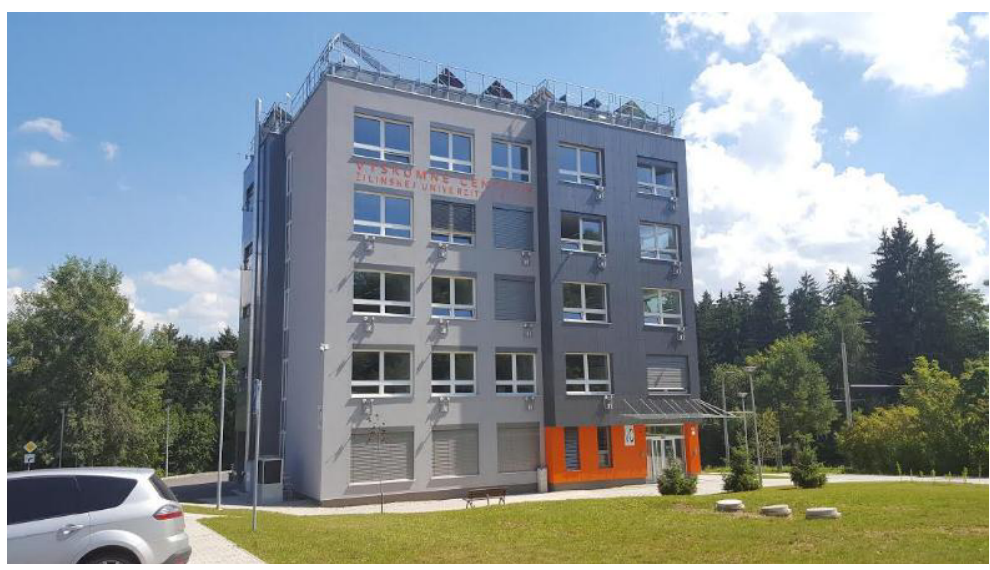

Fig. 3. Picture of the Research Center building in Zilina, view from the west side. 


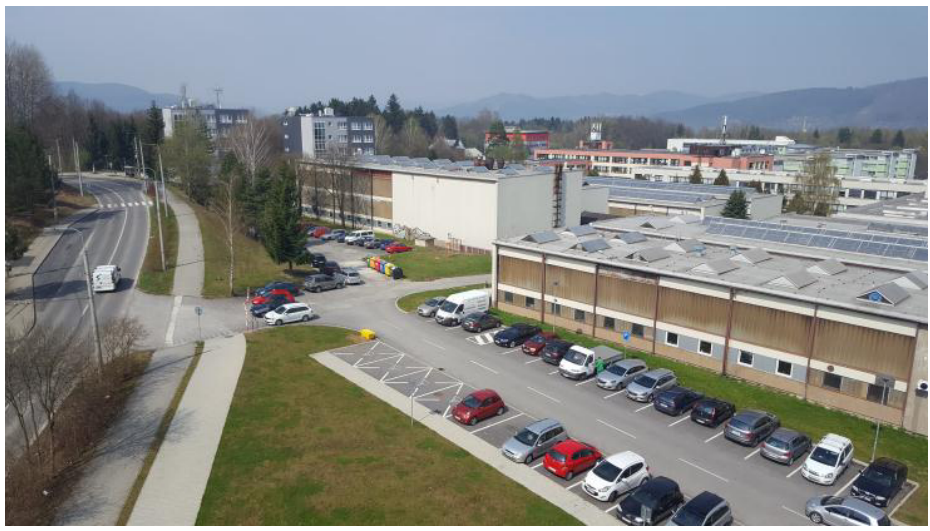

Fig. 4. Picture of the surrounding building to the north-west direction- prevailing wind direction.

\subsection{Meteorological parameters}

The measured values can be compared with data sets from the meteorological station located at Zilina airport (is located approximately $16 \mathrm{~km}$ to the west, belongs to the Slovak Hydrometeorological Institute network) or the experimental detached weather station located on the roof of a nearby building [7]. Obviously, the weather station on the roof cannot be considered as perfect free standing wind-stream because of flow deformation.

\subsection{Instrumentation}

First station works since august 2016, full scale measurements with all 36 stations were conducted since October. Used measurement is from November 2016. 36 meteorological stations are fixed on each side of the building: 3 on the south side at three heights, 14 on the east side at four heights, 15 on the west side at four heights and 4 on the north side at four heights. The marked positions of the meteorological stations are shown in Fig. 5. The exact locations of the stations are summarized in the Table 1. The distances are from the building's edges. Horizontal distance between the middle of the anemometer and facade is $270 \mathrm{~mm}$. View on the façade meteorological station is in Fig. 6.

Table 1. Positions of meteorological stations in full scale, $\mathrm{x}$ in metres from the building edge, $\mathrm{z}$ in metres from the ground.

\begin{tabular}{|r|c|c|c|c|c|c|c|c|c|c|c||}
\hline \multicolumn{5}{|c|}{ distance from the NE building edge } & \multicolumn{5}{|c|}{ distance from the SW building edge } \\
\hline station no. & $\mathrm{x}$ & $\mathrm{z}$ & station no. & $\mathrm{x}$ & $\mathrm{z}$ & station no. & $\mathrm{x}$ & $\mathrm{z}$ & station no. & $\mathrm{x}$ & $\mathrm{z}$ \\
\hline 1 & 14.3 & 8.5 & 10 & 1.1 & 11.3 & 16 & 18.3 & 4.1 & 25 & 6.3 & 4.1 \\
\hline 2 & 10.4 & 7.7 & 11 & 6.4 & 14.9 & 17 & 14.6 & 4.1 & 26 & 1.3 & 7.7 \\
\hline 3 & 14.3 & 12.1 & 12 & 1.1 & 14.9 & 18 & 10.0 & 4.1 & 27 & 6.3 & 11.3 \\
\hline 4 & 10.4 & 11.3 & 13 & 2.6 & 5.1 & 19 & 18.3 & 7.7 & 28 & 1.3 & 11.3 \\
\hline 5 & 14.3 & 15.7 & 14 & 2.6 & 12.3 & 20 & 14.6 & 7.7 & 29 & 6.3 & 14.9 \\
\hline 6 & 10.4 & 14.9 & 15 & 2.6 & 15.9 & 21 & 10.0 & 7.7 & 30 & 1.3 & 14.9 \\
\hline 7 & 6.4 & 4.1 & 34 & 14.6 & 1.9 & 22 & 18.3 & 11.3 & 31 & 2.8 & 8.7 \\
\hline 8 & 1.1 & 4.1 & 35 & 10.8 & 1.9 & 23 & 14.6 & 11.3 & 32 & 2.8 & 12.3 \\
\hline 9 & 6.4 & 11.3 & 36 & 2.7 & 1.9 & 24 & 10.0 & 11.3 & 33 & 2.8 & 15.9 \\
\hline
\end{tabular}



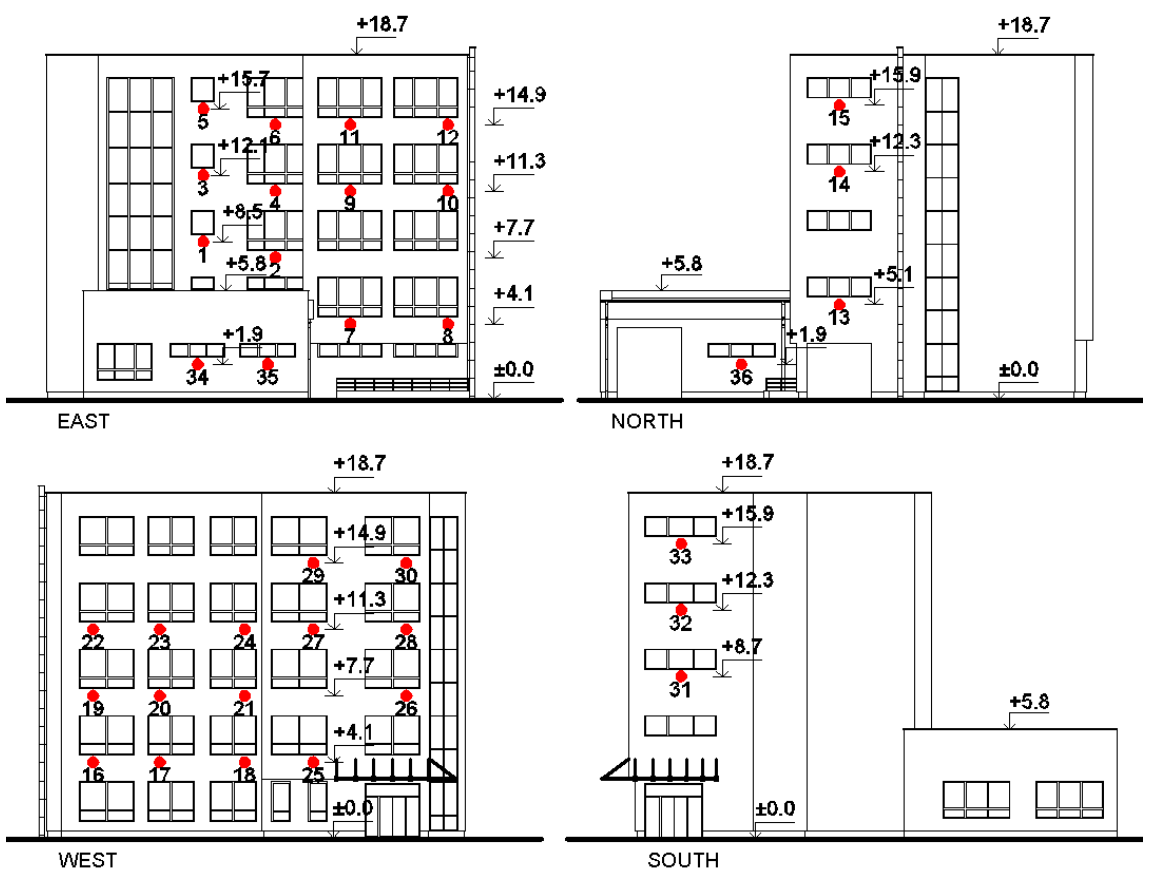

Fig. 5. Schematic view at the Research Centre building with marked and numbered positions of meteorological stations. Rows are marked from the top.

Measured values are collected wireless and transferred to the data storage server located in the building. The measured data are recorded in time steps of 60 seconds. The ultrasonic anemometer has a measuring range up to $40 \mathrm{~m} / \mathrm{s}$, accuracy $+-0.01 \mathrm{~m} / \mathrm{s}$ or $2 \%$ of reading, resolution $0.01 \mathrm{~m} / \mathrm{s}$, readout up-date interval $4 \mathrm{~Hz}$ and response time $250 \mathrm{~ms}$. Measured values of wind velocity and other values are averaged in time, which is 60 seconds.

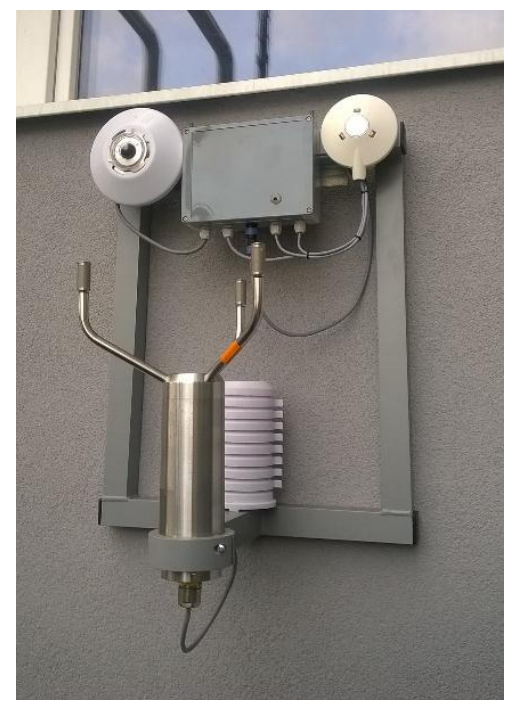

Fig. 6. Meteorological station on the façade consists of anemometer, pyranometer and pyrheliometer and sensor for temperature, relative humidity and air pressure. 


\section{Measurement results}

Wind velocity and direction in the horizontal direction near the building are measured only a few months. However, from these results it is possible to select several days with higher wind speeds (up to $10 \mathrm{~m} / \mathrm{s}$ ) and the steady flow from one direction. Under such conditions we can observe the logical image of wind flow near the façade of five storey office building.

\subsection{Wind speed}

The measured wind speed in the horizontal line at approximately half height of the building (station No. 3, 4, 9 and 10) is documented towards to the distance from the north-east building edge (Fig. 7). Horizontal wind velocity at approximately same height is on Fig. 8.

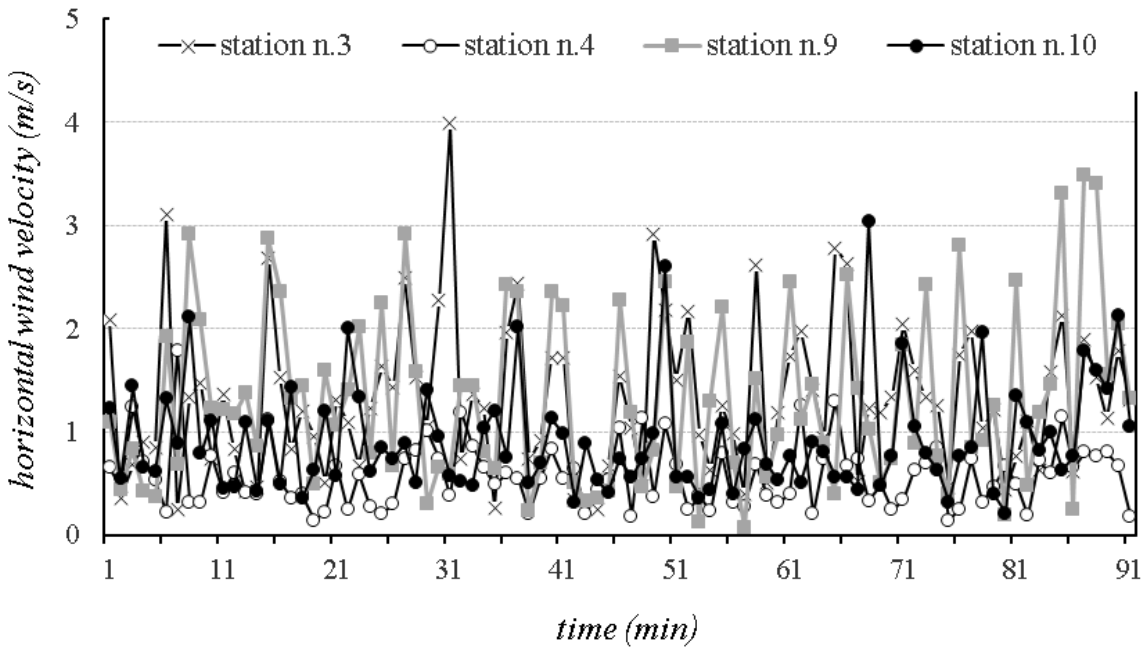

Fig. 7. Measured wind velocity on the east façade of Research Centre building.

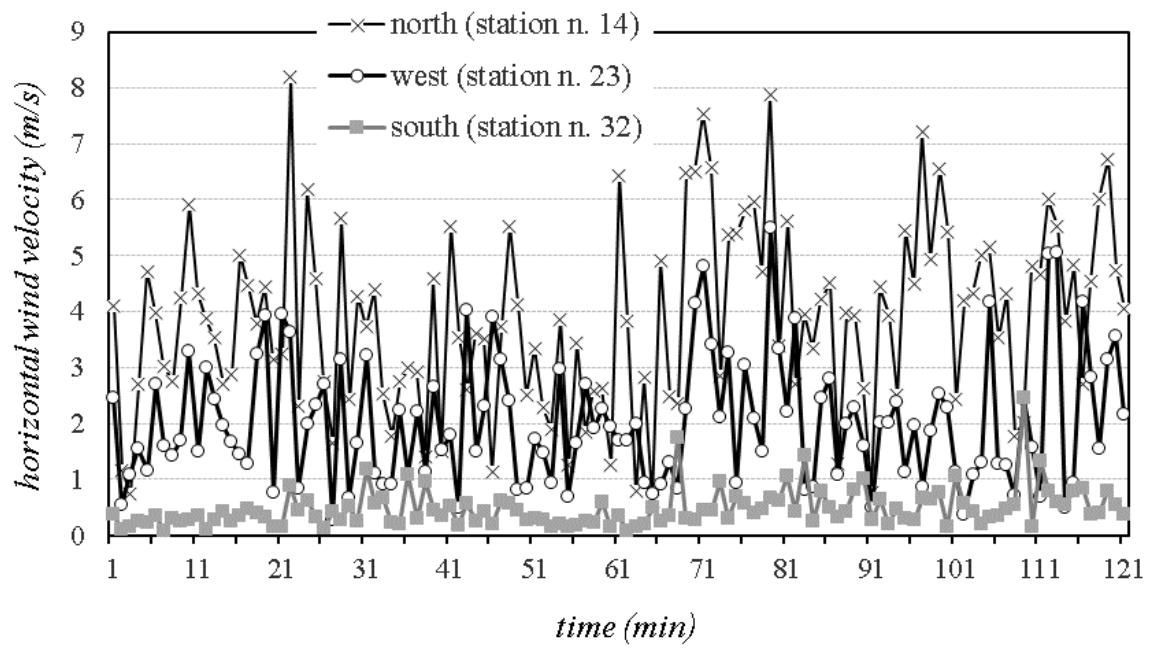

Fig. 8. Measured wind velocity on the façade of Research Center building at height $11.3-12.3 \mathrm{~m}$. 


\subsection{Wind direction}

The measured wind direction at approximately half height of the building is for illustration documented towards to façade orientation (Fig. 9). On the windward side (north) is the wind in almost the same direction. On the leeward sides (west and south) is the wind direction very changeable due to the high turbulence.

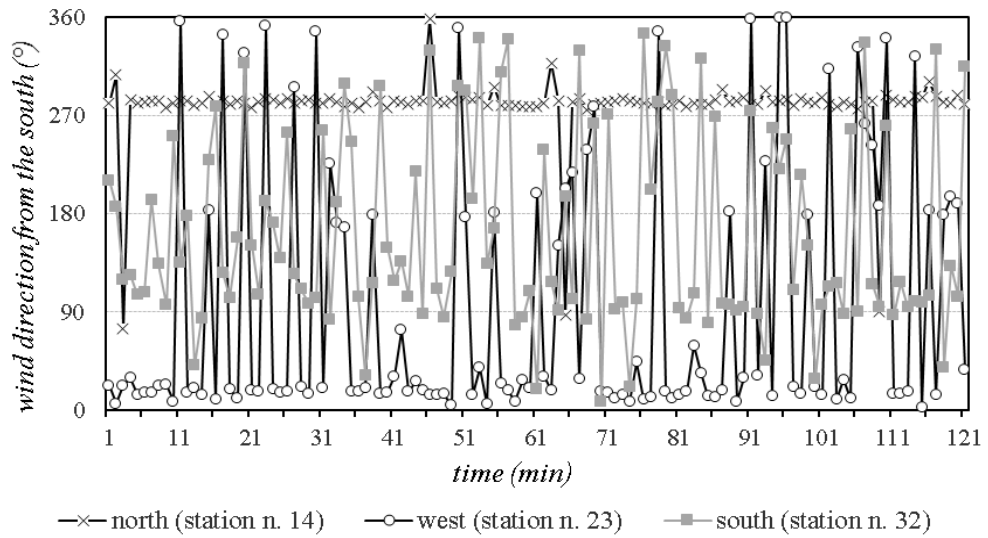

Fig. 9. Measured wind direction on the façade of Research Centre building at height $11.3-12.3 \mathrm{~m}$.

\subsection{Turbulence intensity}

The graph in Fig. 10 describes measured values of wind speed and the turbulence intensity of the facade at one point on the windward side. While the air velocity is higher there is less intensity of turbulence and on the other hand, at the time when the speed is lower, the intensity of turbulence is greater.

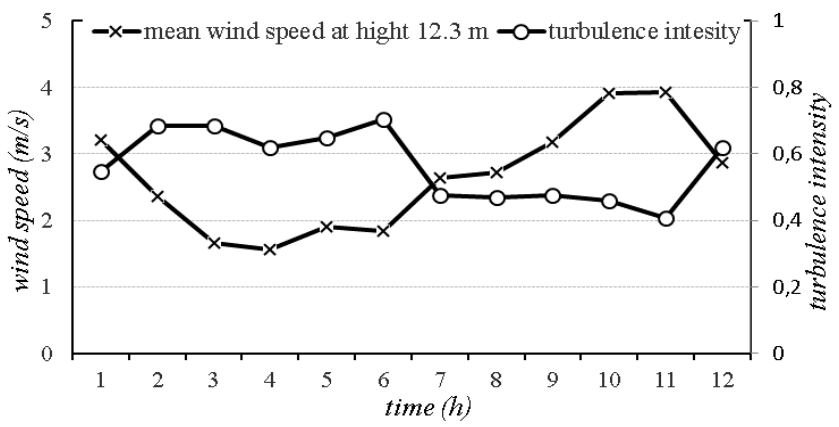

Fig. 10. Intensity of turbulence on the north façade (weather station No.14).

\section{Simulation}

Computational fluid dynamics (CFD) simulations were made before making the final test setup (decision where to fix the stations). Purpose of this simulation was not to compare exact values and comparison between simulation and measurement, because this simulation is far too simplified (surroundings, dimensions of the domain, etc.). But it can provide useful information of flow around the building of this geometry. This simulation was used as a draft for selection of good position on the façade for the meteorological stations. 
For the simulation was used computer software OpenFOAM in version 2.2.0. It is an open-source, implicit, segregated and double precision solver. In the paper, an aerodynamic roughness length of 0.5 is chosen which represents a landscape totally and is quite regularly covered with similar-size large objects according to the Davenport roughness classification [8]. The inlet profile of the mean wind velocity (Fig. 11) is defined by the typical log-law expression [8]:

$$
U(h)=\frac{u_{A B L}^{*}}{k} \ln \left(\frac{y+y_{0}}{y_{0}}\right)
$$

The Aerodynamic boundary layer (ABL) friction velocity, $u_{A B L}^{*}$, is chosen to obtain the desired reference wind speed, $U_{10}$, at a height of $10 \mathrm{~m}$ (in this study $5 \mathrm{~m} / \mathrm{s}$ ). Height of the domain is $100 \mathrm{~m}$ with wind velocity $U_{100}=8.7 \mathrm{~m} / \mathrm{s}$. The inlet wind profile is shown in Fig. 11.

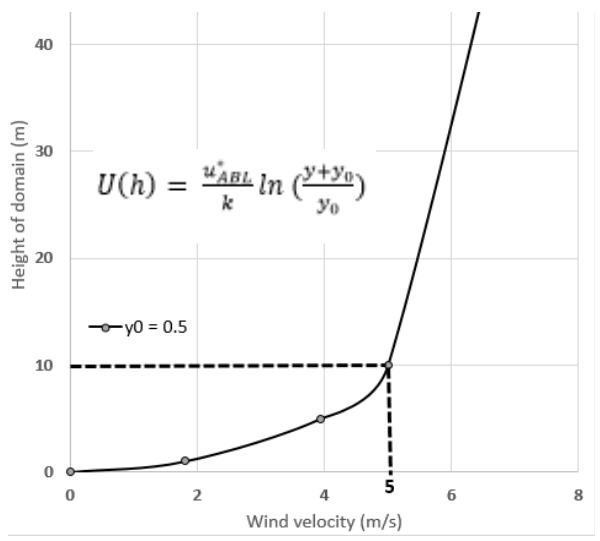

Fig. 11. Wind profile in the used inlet plane of the computation domain, wind velocity $U_{10}=5 \mathrm{~m} / \mathrm{s}$

The computational domain with dimensions $300 \times 450 \times 100 \mathrm{~m}$ consists of 3727272 cells. The cells are mostly hexahedra's with a few polyhedras. The mesh around the building is refined in 4 steps with use of snappyHexMesh tool. Computational domain and refined mesh around the building are in Fig. 12. The blockage ratio of the domain is $0.1 \%$ and the distances of the modelled building among the domain boundaries are according to the guidelines of Franke [9]. Simulated were more variants of wind direction, main flow direction is from south-west, which is represented by the geometry of domain (enough space behind the building for restoration the flow). However in this article is presented case with wind direction which represents west flow.
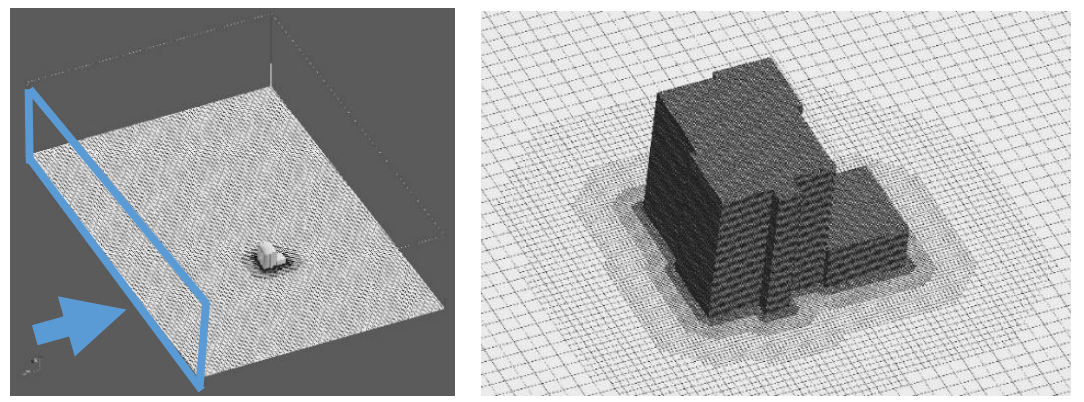

Fig. 12. Computational domain with dimension $300 \times 450 \times 100 \mathrm{~m}$ and marked inlet plane and wind direction, wind velocity $U_{10}=5 \mathrm{~m} / \mathrm{s}$. Refined mesh around the building on the right. 
In Fig. 13, we can see wind flow field and trajectories through the vertical plane in the center of the high part of building. Fig. 14 shows wind flow field at mean wind velocity on the horizontal plane in high $11.3 \mathrm{~m}\left(4^{\text {th }}\right.$ story of the building, $2^{\text {nd }}$ row of the meteorological stations from top).

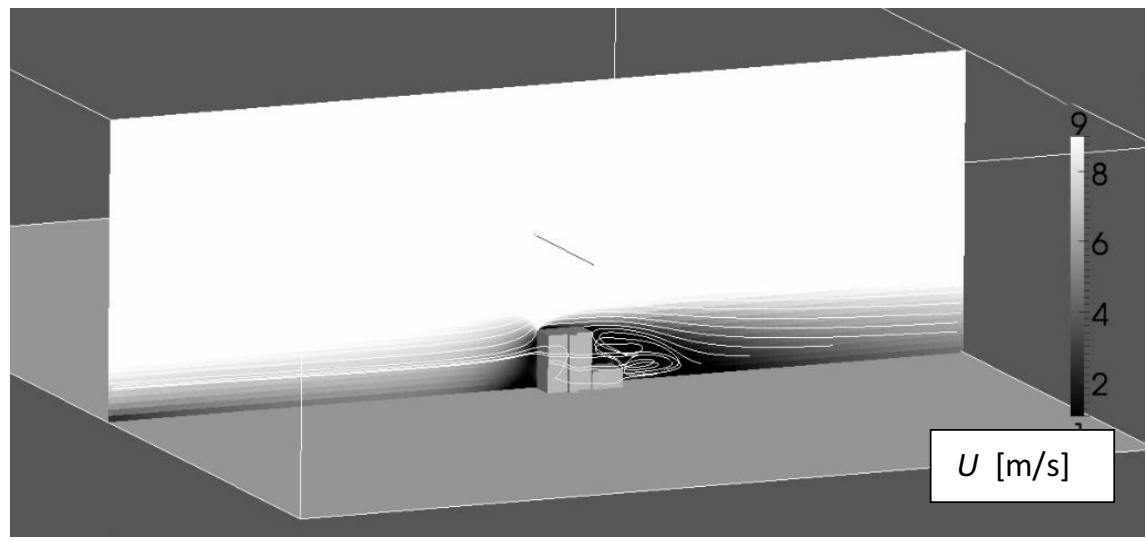

Fig. 13. Wind flow field through vertical plane. Reference wind velocity $U_{10}=5 \mathrm{~m} / \mathrm{s}$.

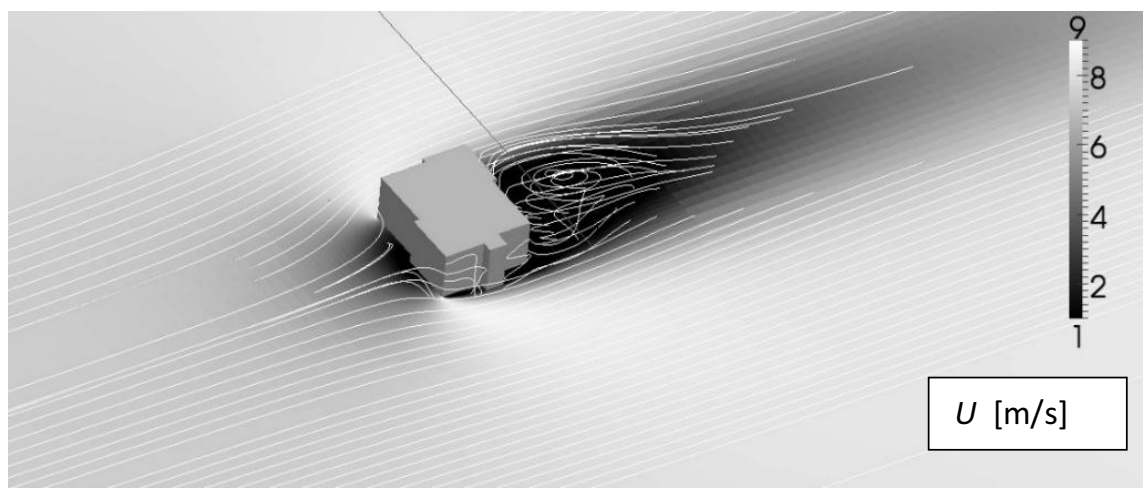

Fig. 14. Wind flow field through horizontal plane at height $11.3 \mathrm{~m}$. Wind velocity $U_{10}=5 \mathrm{~m} / \mathrm{s}$.

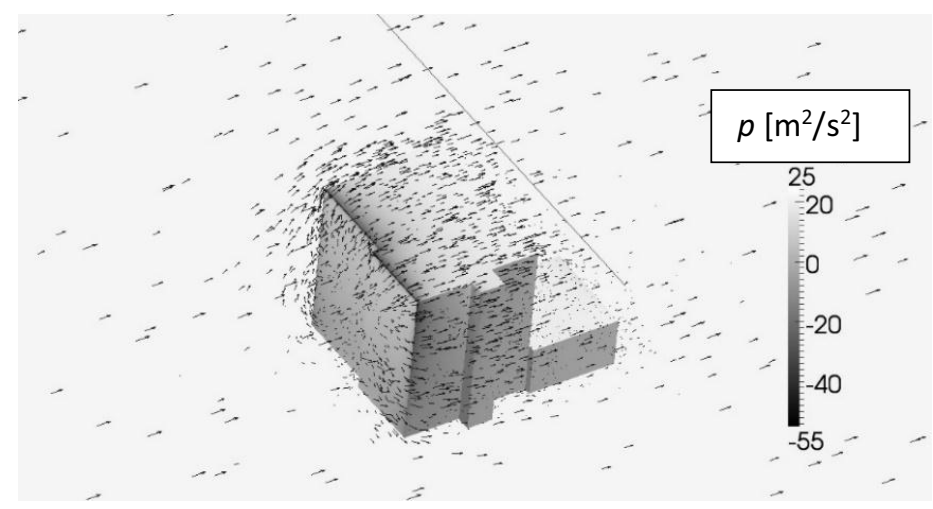

Fig. 15. Pressure on the building inducted by the wind flow and arrows representing wind flow around the building with wind flow from west. Induced pressures are in $\left[\mathrm{m}^{2} / \mathrm{s}^{2}\right]$. 
Influence of the wind flow on the building divide it to several sessions. According to the basic aerodynamics knowledge, approaching flow inducted positive pressure on the windward façade and negative on the other sides (Fig. 15). Typical flow features as the standing vortex, the down-flow from the stagnation point, large vortices behind the building, and flow restoration behind the building are visible (Fig 13 and 14). $2^{\text {nd }}$ row of the meteorological stations on the façade is located in height $11.3 \mathrm{~m}$ above the terrain, which enable the possibility to analyze more precisely the change in the wind velocity from the unobstructed flow (measured generally at height $10 \mathrm{~m}$ above the terrain).

\section{Results and Discussion}

For the design of building structures, the wind loading in the range up to 15 and more years are relevant. This full scale experiment has much shorter period, however, it is important to perform these measurements under atmospheric circumstances with velocities, which are typically in $5-10 \mathrm{~m} / \mathrm{s}$ range, for the wind tunnel experiment or other simulative validation. These tests have a limited applicability, because the reference conditions are often badly measured. Experience shows the relatively high differences between real measurements and wind tunnels are not so uncommon, therefore using the same full scale measurements may help to meet the more relevant values.

In this paper are summarized basic results of the conducted measurement on the façade of Research Centre and showed preliminary CFD simulation which helped with selection of good spots on the façade to set up the measurement. The measurement itself is planned as long-term one.

The research is supported by VEGA No. 1/0945/16.

\section{References}

1. B. Blocken, 50 years of Computational Wind Engineering: Past, present and future, J. Wind Eng. Ind. Aerod. 129, p. 69-102 (2014)

2. V. D. Hoven, Power spectrum of horizontal wind speed in the frequency range from 0.0007 to 900 cycles per hour, J. Meteorology, 14, (1957)

3. Ch. P. W. Geurts, Wind-induced pressure fluctuations on the building Facades, Technische Universiteit Eindhoven, (1997)

4. W. A. Dalgliesh, Comparison of model/full-scale wind pressures on a high-rise building, J. Ind. Aerodynam. 1, (1975)

5. J. D. Holmes, Pressure fluctuation on a large building and along wind structural loadings, J. Indust. Aerodynam. 1, (1976)

6. J. Kanda, Recent developments in full-scale wind pressure measurements in Japan, J. Wind E. Ind. Aerod. 33, (1990)

7. D. Staffenova et al., Importance of using the right climate data sets for needs of energy analysis and choosing the accurate building materials, Modern materials and technologies in sustainable building, (2014)

8. B. Blocken et al., CFD Simulation of the Atmospheric Boundary Layer: Wall Function Problem, Atmos. Environ. 41, (2007)

9. J. Franke et al., The Cost 732 Best Practice Guideline for CFD Simulation of Flows in the Urban Environment: A Summary. Int. J. Environ. Pollut. 44, (2011) 